\title{
Critical Ethnography in Information Systems
}

\author{
M. D. Myers \\ Department of Management Science and Information Systems \\ University of Auckland \\ Auckland, New Zealand
}

Fax: 6493737430

E-mail: m.myers@auckland.ac.nz

\begin{abstract}
In recent years, there has been growing interest in qualitative research methods and their application to information systems. This paper discusses the nature and applicability of one qualitative approach to information systems research, called critical ethnography. Critical ethnography, informed by critical hermeneutics, is one of many possible approaches to ethnographic research. A critical ethnographic study of the development of an information system in mental health is reviewed.
\end{abstract}

\section{INTRODUCTION}

There has been growing interest in qualitative research methods and their application to information systems in recent years. The interest shown is a direct result of the emergence of a certain dissatisfaction with the state of information systems research in the late 1980s and early 1990s. At that time, the most common research methods used in information systems were surveys, laboratory experiments, and descriptive case studies (Alavi and Carlson 1992), which led some researchers to charge that IS research suffered from a lack of diversity (Galliers and Land 1987; Orlikowski and Baroudi 1991). Other researchers claimed that IS research was often superficial and somewhat faddish (Banville and Landry 1989), which is disturbing given the importance and impact of information technology in contemporary society. 
Out of this situation came a call for methodological pluralism in information systems (Avison and Myers 1995; Banville and Landry 1989; Galliers 1991; Hirschheim and Klein 1989; Landry and Banville 1992). Landry and Banville suggested that no single method could ever capture all the richness and complexity of organizational reality, and that a diversity of methods, theories, and philosophies was required (p. 78). Orlikowski and Baroudi, likewise, argued that there was much that could be gained if a plurality of research perspectives was effectively employed to investigate information systems phenomena. They argued that any one perspective is always only a partial view, and unnecessarily restrictive. In line with these calls for methodological pluralism, qualitative (and also interpretive) research methods have gained prominence and been increasingly accepted by the IS research community in the last few years (Benbasat, Goldstein and Mead 1987; Walsham 1993, 1995b; Yin 1989).

The nature and applicability of one qualitative approach to information systems research, called critical ethnography, are discussed in this paper. Critical ethnography, which is one of many possible approaches to ethnographic research, has critical hermeneutics as its philosophical base (Power 1991). Critical ethnography is distinctive in its focus on the relationships among knowledge, culture, society and action (Thomas 1993). The usefulness of the critical ethnographic research method for IS researchers will be illustrated by looking at a critical ethnographic study of the development of an information system in mental health.

The paper is organized as follows. The nature of ethnographic research in general is briefly reviewed in the following section. This is followed by a discussion of critical ethnography in section 3 . Section 4 looks at one critical ethnographic study in some depth, the development of an information system in mental health. Section 5 discusses the findings in the light of the research method used. The final section presents the conclusions.

\section{THE NATURE OF ETHNOGRAPHIC RESEARCH}

An important focus of much recent IS research has been on the social and organizational contexts of information systems design, development and application (e.g., Hirschheim and Newman 1991; Newman and Robey 1992; Walsham 1993). This work has led to the realization that information systems have a highly complex, and constantly changing, social context. It is in the exploration of that social context where ethnographic research comes into its own. The goal of ethnographic research is to improve our understanding of human thought and action through interpretation of human actions in context. For an ethnographer, the preferred way of contributing to an understanding of information systems in organizations is to investigate how they affect social interaction and the creation of shared meanings.

In more traditional positivist techniques, context is treated as either a set of interfering variables that need controlling, known as noise in the data, or other controlled variables, which are experimentally set up in order to seek cause and effect relation- 
ships (Harvey and Myers 1995). The context of a situation is seen as something that can be factored out of the analysis or operationalized as a variable. In ethnographic approaches, however, context is treated as the socially constructed reality of a named group, or groups, of social agents and the key task of observation and analysis is to unpack the webs of meaning transformed in the social process whereby social reality is constructed. For an ethnographer, the context is what defines the situation and makes it what it is. In positivist techniques, cause and effect are the main objects being sought, while in interpretive techniques, meaning in context is the most important framework being sought (Harvey and Myers 1995).

Because context is crucial to qualitative observations and analyses, techniques that explore contextual webs of meaning are important. The two most common qualitative field research methods for doing this are interpretive in-depth case studies (Walsham 1993) and ethnographies (Hutchins 1995; Star 1995; Suchman 1987; Wynn 1979, 1991; Zuboff 1988). Although there is no hard and fast distinction, the principle difference between the two depends upon the length of time that the investigator is required to spend in the field and the extent to which the researcher immerses himself or herself in the life of the social group under study. In a case study, the primary source of data is interviews, supplemented by documentary evidence such as annual reports, minutes of meetings and so forth. In an ethnography, these data sources are supplemented by data collected during participant observation on the part of the researcher over an extended period of time. The ethnographer "immerses himself in the life of people he studies" (Lewis 1985, p. 380) and seeks to place the phenomena studied in its social and cultural context. As Yin explains,

Ethnographies usually require long periods of time in the "field" and emphasize detailed, observational evidence. . . In contrast, case studies are a form of enquiry that does not depend solely on ethnographic or participant observation data. One could even do a valid and high-quality case study without leaving the library and the telephone. [Yin 1989, p. 21-22]

The difference between an in-depth case study and an ethnography can be illustrated from the IS research literature. The ethnographic research method was used by Orlikowski (1991), who studied a large, multinational software consulting firm over eight months. Data was collected via participant observation, interviews, documents, and informal social contact with the participants. The in-depth case study method was used by Walsham and Waema (1994), who studied a building society for a period of two years. The principal method of data collection was in-depth interviews with a range of organizational participants. The researchers did not use participant observation.

In recent years, a small but growing number of information systems researchers have recognized the value of the ethnographic method for information systems research (Harvey and Myers 1995; Lee 1991; Lee, Baskerville and Davies 1992; Pettigrew 1985; Wynn 1991). Some of the early ground-breaking work was done by Wynn (1979) in her study of office conversations, Suchman (1987) in her study of the 
problem of human-machine communications, and Zuboff (1988) in her study of the automating and "informating" potential of information technology.

Since then, ethnography has become more widely used in the study of information systems in organizations, from the study of the development of information systems (Hughes, Randall and Shapiro 1992; Orlikowski 1991; Preston 1991; Suchman 1995) to the study of aspects of information technology management (Davies 1991; Davies and Nielsen 1992). Ethnography has also been discussed as a method whereby multiple perspectives can be incorporated in systems design (Holzblatt and Beyer 1993). For example, Bentley et al. (1992) conclude that ethnographic studies "are helpful in informing the systems design process and may produce insights which contradict conventional thinking in systems design" (p. 123).

In the area of the design and evaluation of information systems, some very interesting work has been taking place in a collaborative fashion between ethnographers, on the one hand, and designers, IS professionals, computer scientists and engineers on the other. This collaborative work is especially strong in the UK and Europe and is growing in the US (Star 1995). For example, one of the main projects of the group at Lancaster University (Hughes, Shapiro and Rodden) has been to use the ethnographic method to gain an understanding of human cooperation in air traffic control (Bentley et al. 1992; Hughes Randall and Shapiro 1992).

Having briefly reviewed the nature of ethnographic research in general and its use in the IS field, attention will now be given to the distinctive features of critical ethnography.

\section{CRITICAL ETHNOGRAPHY}

Although all ethnographic research is similar in the sense that the ethnographer is required to spend a significant amount of time in the field, there are many different schools or views within anthropology about ethnographic interpretation and there is critical debate within anthropology concerning the ethnographic research method (Van Maanen 1988). These different views about ethnographic research are relevant to the ethnographic study of information systems as they show the variety of approaches which have been adopted within the source discipline. Although unable to discuss this critical debate within anthropology in depth here, one of the landmark publications in this debate is the work of Clifford and Marcus (1986; see also Clifford 1988; Marcus 1992).

Sanday (1979) divides ethnography into the holistic, semiotic, and behavioristic schools of thought, and she further divides the semiotic school into thick description and ethnoscience. Each school of thought has a different approach to doing an ethnography. For example, most ethnographers of the holistic school say that empathy and identification with the social grouping being observed are needed; they insist that an anthropologist should "go native" and live just like the local people (e.g., Evans-Pritchard 1950; Cohen 1985). The assumption is that the anthropologist has 
to become like a blank slate in order fully understand local social and cultural practices. The anthropologist acts like a sponge, soaking up the language and culture of the people under study.

On the other hand, Geertz, the foremost exponent of the "thick description" (semiotic) school, says that anthropologists do not need to have empathy with their subjects (Geertz 1973, 1983, 1988). Rather, the ethnographer has to search out and analyze symbolic forms - words, images, institutions, behaviors - with respect to one another and to the whole that they comprise. Geertz argues that it is possible for an anthropologist to describe and analyze another culture without having to empathize with the people. He says that anthropologists need to understand the "webs of significance" which people weave within the cultural context, and these webs of significance can only be communicated to others by thickly describing the situation and its context.

An alternative to the above is the adoption of a critical perspective on ethnographic research, called critical ethnography. Critical ethnography has emerged as one important approach to ethnographic research (Marcus and Fischer 1986; Thomas 1983, 1993; Power 1991). For example, Forester (1992) used critical ethnography to examine the facetious figures of speech used by city planing staff to negotiate the problem of data acquisition. Myers (1987) used critical ethnography in his study of the independence movement in the Melanesian nation of Vanuatu.

The critical ethnographic approach to interpretive field research is discussed below. Since critical ethnography has critical hermeneutics as its underlying philosophical base, critical hermeneutics will be reviewed first.

\subsection{Critical Hermeneutic}

Critical hermeneutics is an integrative philosophical approach, combining interpretive and critical elements (Thompson 1981; Myers 1994, 1995). Critical (or dialectical) hermeneutics is an attempt to dissolve the boundaries between the interpretivist and critical research traditions, which have usually been seen as quite distinct (Orlikowski and Baroudi 1991). The philosophical basis for integration is provided by Bernstein (1983), who argues that there is common ground between the critical theory of Jurgen Habermas and the hermeneutics of Hans-Georg Gadamer. Hoy (1988), likewise, argues that it is possible to integrate the interpretive and critical approaches. Hoy finds that the writings of Paul Ricoeur provide such an integrative perspective.

What follows, then, is a description of critical hermeneutics as an integrative philosophical perspective. In this discussion, critical hermeneutics will be distinguished from "pure hermeneutics" as it has been traditionally represented.

Hermeneutics is the science of interpretation, concerned with analysis of the meaning of a text or text-analogue. The basic question in hermeneutics is "What is the meaning of a text?" (Radnitzky 1970, p. 20). Taylor says that

Interpretation, in the sense relevant to hermeneutics, is an attempt to make clear, to make sense of an object of study. This object must, therefore, be 
a text, or a text-analogue, which in some way is confused, incomplete, cloudy, seemingly contradictory - in one way or another, unclear. The interpretation aims to bring to light an underlying coherence or sense. [Taylor 1976, p. 153]

The idea of a hermeneutic circle refers to the dialectic between the understanding of the text as a whole and the interpretation of its parts, in which descriptions are guided by anticipated explanations (Gadamern 1976, p. 117). As Gadamer explains, "It is a circular relationship....The anticipation of meaning in which the whole is envisaged becomes explicit understanding in that the parts, that are determined by the whole, themselves also determine this whole."

The idea of the hermeneutic circle can be applied to the way in which we understand an organization as a text-analogue. In interpretive research, the movement of understanding "is constantly from the whole to the part and back to the whole"; in other words, the more interviews we conduct and the more information we gather, the more we understand the organization as a whole and its constituent parts. This hermeneutic process continues until the apparent absurdities, contradictions and oppositions in the organization no longer appear strange, but make sense.

It follows from this idea of the hermeneutic circle that we have an expectation of meaning from the context of what has gone before. The movement of understanding "is constantly from the whole to the part and back to the whole" (Gadamer 1976b, p. 117). Ricoeur points out that "Interpretation... is the work of thought which consists in deciphering the hidden meaning in the apparent meaning, in unfolding the levels of meaning implied in the literal meaning" (Ricoeur 1974, p. xiv).

In the last ten years, hermeneutics has been taken up by researchers in the information systems area (e.g., Winograd and Flores 1987; Lee 1991, 1994; Boland 1985, 1987, 1991; Boland and Day 1989; Myers 1994, 1995). The principles of hermeneutics have been applied to analyses of the metaphorical nature of theories of information (Boland 1987) and to systems development (Hirschheim and Newman 1991). Hermeneutics is a recognized framework for the analysis of organizations (Bryman 1989), in particular when looking at organizational culture (Frost et al. 1985), and has been applied to the analysis of socio-technical interactions (Barley 1986).

There are different forms of hermeneutics, all concerned with the textual treatment of social settings, but not all concern themselves with reflective critique of the meaning of interpretations derived from textual analyses. The early hermeneuts such as Dilthey advocated a "pure hermeneutics" which stressed empathic understanding and the understanding of human action from the "inside." As Radnitzky (1970, p. 20ff) points out, however, pure hermeneutics is uncritical in that it takes statements or ideologies at face value." He cites Gadamer as saying that "we don't have to imagine oneself in the place of some other person; rather, we have to understand what these thoughts or the sentences expressing them are about."

More recently, critical hermeneutics has emerged following the debates between Habermas and Gadamer (Gadamer 1976a; Ricoeur 1974; Thompson 1981; Myers 1995). There is a potential tendency to view interpretation as a closed and exact form, 
but critical hermeneutics recognizes that the interpretive act is one which can never be closed as there is always a possible alternative interpretation (Taylor 1976). In critical hermeneutics, the interpreter constructs the context as another form of text, which can then, of itself, be critically analyzed so that the meaning construction can be understood as an interpretive act. In this way, the hermeneutic interpreter is simply creating another text upon a text, and this recursive creation is potentially infinite. Every meaning is constructed, even through the very constructive act of seeking to deconstruct, and the process whereby that textual interpretation occurs must be selfcritically reflected upon (Ricoeur 1974). The close relationship between critical hermeneutics and critical ethnography serves to "emphasize the sense in which all social inquiry is exploratory and open" (Power 1991, p. 338).

Critical hermeneutics also recognises that prejudice, prejudgement or prior knowledge plays an important part in our understanding. In positivist social science, prejudice or prejudgement is seen as a source of bias and therefore a hindrance to true knowledge; objectivity, according to positivism, is best attained if a social scientist adopts a value-free position and does not let biases interfere with his or her analysis. By contrast, hermeneutics recognizes that prejudice is the necessary starting point of our understanding. The critical task of hermeneutics then becomes one of distinguishing between "true prejudices, by which we understand, from the false ones by which we misunderstand" (Gadamer 1976b, p. 124). Of course, the suspension of our prejudices is necessary if we are to begin to understand a text or text-analogue. But as Gadamer points out, this does not mean that we simply set aside our prejudices. Rather, it means that we, as researchers, must become aware of our own historicality (p. 125). This awareness of the dialogue between the text and the interpreter is peculiar to contemporary hermeneutics. The earlier hermeneutic philosophers such as Dilthey ignored this dialogical relationship between the text and the interpreter and attempted to understand the objective meaning of a text in its own right.

\subsection{Toward a Critical Ethnography}

Adoption of critical hermeneutics as one's underlying philosophical position in ethnographic research leads to criticism of nondialectical views of ethnographic work. One such nondialectical position is that of the holistic school in ethnography. Ethnographers of the holistic school, in their attempt to "go native" and understand other cultures "in their own terms," in effect deny the glossing of those views by the interpretive act of the analyst. The end result is tantamount to a recourse to objectivity due to a taking for granted of the need for the critical analysis of the dialectics of the interpretive process. The role of the observer is treated as context-free, ignoring the fact that every interpretive exploration leads to a new understanding, thus rendering history as the most vital attribute of ethnographic analysis, the history of the material and the history of the interpretation. For example, in Zuboff's study of computer-mediated work, the historical nature of the ethnographic work was regarded as fundamental to the ethnographic work being carried out. She argued that "history 
would offer only a brief window of time during which such data could be gathered" (Zuboff 1988, p. xiv).

The critical hermeneutic perspective thus openly recognises that understanding of an institutional context is not gained by the researcher suspending her or his prejudices. Rather, the ethnographer is encouraged to become critically aware of them, making them explicit in the process of learning about the organization.

The critical hermeneutic perspective leads to the recognition that any interpretive field research is a form of historiography. The researcher is essentially situated in history, the history of the situation and of the interpretation, and is also part of a wider set of social, economic and political relationships. One of the key tasks of a researcher is to be aware of the historical context in which research takes place and to critically reflect this onto the research process itself. In arguing for a reflexive anthropology, Kahn (1989) points out that the interpretation of culture(s) "is in fact part of a process of construction" and says that anthropologists themselves "are similarly part of a broader socio-historical process" (p. 22; see also Scholte 1972).

To put the argument in another way, when I, or any other anthropologist, produces in text an account of another culture, what I am in fact doing is engaging in a process with a history. That history is the cultural product of a longstanding relation between "us" and "them" within which I and my "informants" are embedded. At the same time, the knowledge which I/we produce out of that relation - in my case for example the knowledge I might choose to term "Minangkabau culture," or "the meaning of mosque symbolism in a West Sumatran village," or whatever - is new knowledge in the sense that it does not pre-exist in West Sumatra, hard-wired as it were in the brains of the Minangkabau from time immemorial. It exists, and can only exist, in the relationship between Minangkabau and the West. [Kahn 1989, p. 16]

This awareness of the importance of history leads to criticism of the "ethnographic present," a standard device used by many anthropologists to describe social and cultural practices. The ethnographic present gives the (false) impression that the activities being described have always existed from time immemorial. The use of such phrases as "the development process starts out each September" or "all the members of the development team do not participate" gives the distinct impression that such activities have taken place since the world was created. The ethnographic present is thus ahistorical, and neglects to mention when these activities were instituted. The ethnographic present ignores how human actions are always situated in history.

Although critical ethnography is distinctive, it does not stand in opposition to other forms of ethnographic research. Rather, it is a type of reflection about the relationships among knowledge, culture, society and action (Thomas 1993). "Critical ethnographers describe, analyze, and open to scrutiny otherwise hidden agendas, power centers, and assumptions that inhibit, repress, and constrain. Critical scholarship requires that commonsense assumptions be questioned" (Thomas 1993, pp. 2-3). In 
a critical ethnography, the critical analysis moves beyond the immediate narrative of the subjects to the broader processes within which the narratives are embedded. Further guidelines for doing critical ethnography can be found in Thomas (1993).

\section{A CRITICAL ETHNOGRAPHIC STUDY OF THE DEVELOPMENT OF AN INFORMATION SYSTEM IN MENTAL HEALTH}

A critical ethnographic study of the development of an information system in mental health will now be reviewed. This ethnographic study, conducted by Young (1995) under the supervision of Michael D. Myers at the University of Auckland, was concerned with the development of an information system in mental health. This information system, developed during 1994 and the first part of 1995, was developed for Mental Health in one of the Crown Health Enterprises in New Zealand. The ethnographic research took place over a period of ten months, from April 1994 to January 1995. The ethnographic material was collected via participant observation, structured and unstructured interviews, unpublished documents (such as minutes of meetings), and newspaper and magazine reports (Young 1995). Some information about the health sector in New Zealand and the organization will be summarized first, with the objective of setting the specific IS project within its broader social and historical context. This will be followed by a discussion of one of the key issues which emerged during development.

\subsection{The Health Sector in New Zealand}

The New Zealand health care system is made up of public, private and voluntary sectors that interact in financing and providing medical care. Total expenditure on health care in New Zealand of NZ $\$ 4,873$ million in $1989 / 90$ was funded in the proportions of $\$ 4,150$ million by the government, and $\$ 723$ million by the private sector (Danzon and Begg 1991). Funding was provided by the Department of Health, Accident Compensation Corporation (ACC), budget allocations and levies, individuals, private insurance premiums, insurance managed by employers and other organisations (such as unions), as well as out-of-pocket payments by patients.

New Zealand's public hospitals, which number around 175, are mostly administered by Crown Health Enterprises (CHEs). These public hospitals provide around 23,000 beds or about $80 \%$ of the total hospital beds in New Zealand. Services are provided to inpatients at zero monetary cost although costs are incurred in terms of waiting for an appointment for treatment, as well as waiting times once appointments have been made, and limitations in the quality of service provided to patients (Danzon and Begg 1991). There is a NZ $\$ 31$ charge per visit for outpatients. 
The public sector, through the Ministry of Health, provides free treatment for all New Zealand citizens at public hospitals, long term care and public health services. Private hospitals have evolved to provide services not adequately provided by the public sector, notably elective surgery and geriatric care. The voluntary sector includes such organizations as the Intellectually Handicapped Society, Plunket Society, Family Planning Association, Salvation Army and the Crippled Children Society. Some of these receive government assistance (Danzon and Begg 1991).

The health sector in New Zealand has, over the years, undergone many changes in administration and information technology. The changes have been somewhat more radical in recent years with major changes to the social and political structure of the New Zealand Healthcare system. In 1991, the New Zealand Government signaled a major reform to the health system, the key to which was the so-called "purchaserprovider split." Under this arrangement, the existing Area Health Boards were dismantled and replaced by a combination of Regional Health Authorities (RHAs) and Crown Health Enterprises (CHEs). The RHAs became responsible for the purchase of health care from institutions and practitioners within its region,(Clausen, Domney and Pederson 1992). Crown Health Enterprises (CHEs) and community trusts became responsible for the provision of health services to the community (Upton 1991).

The main objective of the government's reform was to introduce competition into the health sector in the hope that this would reduce costs and improve the productivity of the health industry: In essence, the government created a competitive market whereby the RHAs purchase health care services from providers who compete with each other. However, the introduction of market principles into the health arena was strongly opposed by most other political parties and many doctors and nurses. Doctors and nurses often vented their anger and frustration at the reforms in the mass media, arguing, for example, that patients should not be viewed as customers. For them, the word customer was suggestive of a more impersonal kind of relationship based on the payment of a fee, as contrasted with the word patient, which for them implied a more personal kind of relationship based on concern for a person's wellbeing.

Nevertheless, with the emergence of a competitive market being a foregone conclusion, senior management in the CHEs saw the need to develop new information systems to help them compete for contracts. Senior managers realised that accurate cost and output information as well as information relating to service quality measures were needed if their organization was to be successful in the competitive bidding process (Myers and Young 1995). These newly developed information systems thus became one of the key instruments by which senior management could achieve the purported benefits of the government's reforms. 


\subsection{The Organization}

Sky City Health (a pseudonym) is a Crown Health Enterprise in a New Zealand city, providing health services to the public. Sky City Health's vision statement reads as follows:

Through innovation and dedication to the service of our patients, we will provide health care solutions that are measured as successful by the patient, the health care team and the organisation.

To provide successful health care solutions we need to provide the right care, in the right amount, at the right time and in the right setting.

The organization has introduced the concept of shared values. The shared values include patient and user focus, professionalism, integrity, taking personal responsibility, service orientation, teamwork, innovation, communication, confidentiality and cultural sensitivity.

Sky City Health used to have a very hierarchical organizational structure, but in recent years this has become somewhat flatter. The chief executive officer is responsible to a board of directors. Five general managers report to the CEO, one of whom is the group manager for mental health services. Information services has no group manager; instead it comes under the responsibility of the general manager for finance and commercial (Myers and Young 1995).

\subsection{Information Services}

Information services is a separate unit in Sky City Health responsible for overseeing all information systems projects. he IS unit has identified three key critical success factors in relation to the successful implementation of information technology:

- Alignment of IT strategy with the organization's business plan.

- To put in place an architecture providing flexibility in case of future business change.

- Not to continue with current business practices that are inconsistent with new technology and/or new systems.

Other issues that have been identified as important are using information technology to add value to the organization, treating information technology as an asset, automating critical and commonly used parts of the existing medical record, and recognising quality service.

At the time of the research, information services used a project plan document to ensure a consistent methodology for the implementation of all projects undertaken by Sky City Health. These projects mainly arise through their information systems strategic planning exercise, but may include any other information systems projects that arise from time to time.

The key areas of the project methodology are

- definition of responsibilities for implementation 
- confirmation of the deliverables

- development of the project plan(s)

- meeting schedules

- change control

- purchase of the componentry

- monitoring of implementation

- acceptance

- project closure

- post project review

Generally, project teams are comprised of a project director, a projeçt sponsor, a project leader and one or more project champions, business analysts and technical resource personnel (if appropriate). Other parties likely to be involved in the project include vendors.

As part of the project team framework, an information systems steering group has been set up to provide a forum for directing, monitoring and reviewing information systems projects. The meetings are held once a month. The members are drawn from senior management, clinical services disciplines, operations and management support, and information services (Myers and Young 1995).

\subsection{The Mental Health IS Project}

Mental health services in Sky City are split into two categories of health care users: inpatients and outpatients. Inpatients are health care users who are admitted to a facility and stay for more than four hours, whereas outpatients are referred from other services or general practitioners to a particular service and leave the service on the same day. Two hospitals provide inpatient services for adults, whereas outpatient services are provided in three areas of the community.

In 1993, a functional specification for a management information system for mental health was compiled, and a request for information (RFI) for a mental health information system was sent out to vendors in 1994. Some of the requirements were

- to improve the quality of care given

- to improve management reporting

- to improve communications

- to improve personal care

- to improve efficiency

A number of clinical issues were required to be addressed by the information system:

- There is a need to record information at a level determined by the health care providers (HCP).

- There is a need to record clinical information on an event-by-event basis where it is regarded as important by the recording HCP.

Following the receipt of responses to the RFI, vendors were put on a short list. Only vendors that could potentially deliver a complete solution (including administrative and clinical functions) were considered. However, after some evaluation it was 
concluded that there did not seem to be any vendor that could technically and functionally deliver a complete system. Of the vendors looked at, none of them could provide for Sky City Mental Health's specific requirements, nor did they comply with New Zealand regulations. In view of the fact that nothing suitable was found, it was decided by information services that it would be far cheaper and faster to develop an interim system inhouse.

After an information strategic steering group meeting and subsequently a board meeting, it was decided that the overall strategic IS direction would be to split the proposed solution into three parts: core/administration, clinical and casemix. A request for proposal would be issued to vendors for clinical solutions, while the core/administration functions for mental health would be developed inhouse by information services at Sky City Health. Casemix would be tendered for separately. Figure 1 depicts the structure of the proposed information systems architecture and shows how it would be split.

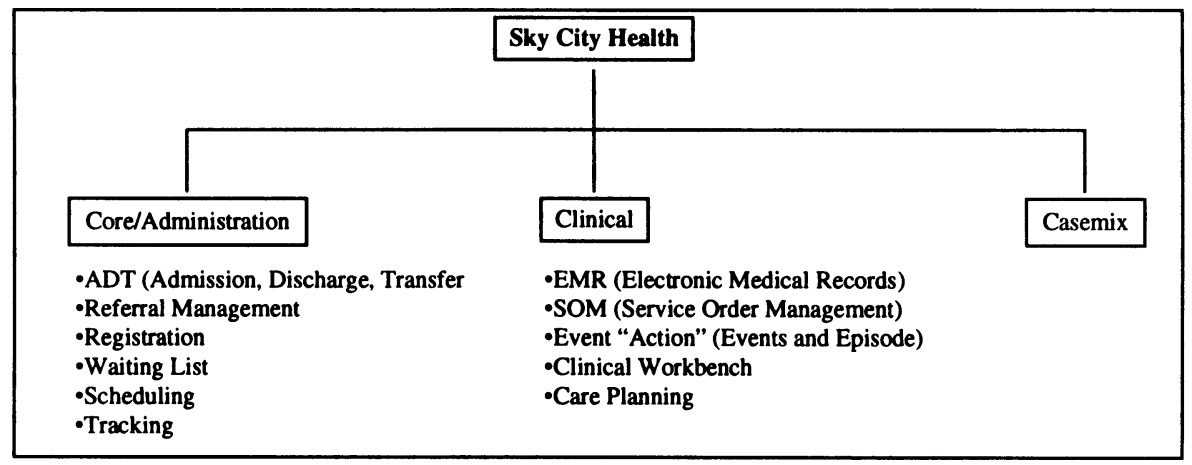

Figure 1 Sky City Health's IS Architecture (Adapted from Young 1995).

The core/administration functions to be covered by the inhouse IS project were the registration, referral, initial assessment, medical administration, tracking and exit modules. Added to that was a financial module dealing with the trust facilities currently provided by one of the hospitals for its health care users.

Consistent with the IS project methodology a project team for the mental health project was formed. The members of the project team represented all of the major stakeholder groups within Sky City Health's Mental Health services. The team consisted of the following: two project sponsors (group manager of mental health, and the clinical director); project leader - information services; project developer information services; operations coordinator - group manager's office; medical records officer; psychiatrist district nurse - crisis unit; one clerical staff person; one psychiatrist; one charge nurse - acute service; one clinical psychologist. The project 
team had regular meetings once a week, after which the project leader reported to the project coordinator, who then reported to the IS manager, also on a weekly basis.

Throughout the course of the mental health project, the project team experienced a number of changes in membership. The project leader changed once and the project coordinator changed three times. Toward the end of the project, one of the user group members left the organisation and was replaced by two other users (the user group is discussed below). During the year the project developer from information services left and was replaced by a project developer from system support group to complete the project.

A user group composed of six members was formed in May 1994 to represent clerical staff and clinicians. The user group's role was to make sure that user requirements were considered throughout the project and to review the prototypes.

\subsection{An Analysis of One Key Issue: Time-Based Costing}

Space does not permit a full discussion of many of the issues which emerged during the project, therefore just one key issue will be discussed here: time-based costing.

It was suggested earlier that new information systems were proposed by senior management in many Crown Health Enterprises so that accurate cost and output information as well as information relating to service quality measures could be obtained. In Sky City Health, these information systems (of which the mental health system was but one) were seen as essential if the organisation were to be successful in the newly instituted competitive bidding process. The mental health IS project was thus intimately tied up with the government's reforms. The IS project was the means by which mental health in Sky City could be transformed into an effective and efficient business enterprise. In effect, the proposed mental health information system, to use the language of Broadbent, Laughlin and Read (1991), was a "steering mechanism" to steer the social system of mental health in a direction aligned to the goals of the New Zealand government. The new IS represented the introduction of market principles to the mental health arena.

However, significant numbers of clinical staff opposed the government's reforms in the health sector, and by implication the information systems that were to be developed to put these reforms into practice. Information services, charged by senior management with developing the new mental health IS, faced the problem of recruiting and retaining doctors and nurses to serve on the project team and on the user group. It was essential for doctors and nurses to participate in the development of the project if information services were to be consistent in their use of the IS development methodology. Participation was also seen to be essential if the new system were to be accepted by clinical staff.

In the mental health IS project, one important module was called "time-based costing." There was much discussion and major disagreements which centered around the development of the "time-based costing" module. Briefly, time base costing is the recording of hours utilized by clinicians, involving a costing report which can be used 
to estimate how much funding is required from the government. Senior management regarded time-based costing as an essential part of the new system, while many doctors and nurses saw this as a threat to their professional status and conditions of employment. Clinicians tended to see time-based costing as an attempt by management to treat them like factory workers.

In a user group meeting near the end of the project, the champion (a senior manager) explained time based costing to the clinical users as follows:

There has been acknowledgment for some time that there hasn't been any measures of what we actually do. And this information is used by the financial department, which contract our services....[The lack of data] is more of a worry because, when one does hone in, you can't compare one home visit to another home visit - the number of variables could be huge. In mental health services in particular, our technology is our staff, not like radiology where you can talk about scans, you can attribute the amount of endorsers to the running of one X-ray, or one ultrasound or something like that. Our staff and staff time, that is the main cost driver for mental health ...I know there has been a history in the past to try and collect time based units, and that has certainly happened in other areas....So $\mathrm{A}$ and I sat down and tried to look at a way we could collect information based on time, that wasn't going to be unwieldy, not going to be difficult for staff and create major barriers....We are not talking about this as hidden information. What we see is a report coming up monthly - not that we are going to an individual level at this stage, it might be by professional group, or by location.

From the above statement, we can gather that this senior manager tried to minimize the importance of time-based costing to the clinical users (e.g., "we are not talking about this as hidden information"; "not that we are going to an individual level at this stage") while saying that it was very important for financial reasons. Senior management tended to regard the implementation of time-based costing as a certainty.

Interestingly, however, time-based costing was never included in the original user requirements document written in May 1994. Neither was it mentioned in the functional overview dated June 1994 or the updated user requirements of January 1995 (although it was mentioned verbally at a user group meeting). From the point of the view of information services, the project leader expressed the view that the issue was a business issue and not an IS issue. The onus would be on the user group to sort it out with management at a later date. The project leader stated that she preferred to have the time-costing module included later once the full system was in place. Clearly, both senior management and information services intended that the timebased costing module would be an integral part of the new mental health information system, but for political reasons the importance of this particular module was minimized and omitted from the initial user requirements documents.

The following is a transcript of a user group meeting when the time-based costing module was mentioned by the project leader from information services for the first 
time. The project leader had just informed the usergroup members that time-based costing should now be included in the official user requirements document.

User 1: So has that project been slipped into our brief as well?

IS: Yes, that will be included, and after tracking is the patient exit ...

User 1: I am not happy actually with the time base costing going in ...

IS: That is a very small module..

User 1: Well, we might think it is small, maybe it is small in terms of the thing we are bringing in. But when we take this product out to the users, that time base costing is going to seem this big, and the rest is going to seem this big, and they are going to be saying "Oh, so that's why they are setting up this thing!"

IS: No it is very small, it's just a print-out that's all.

User 1: I know, but ...

User 2: You're worried about resistance.

User 1: I am worried about perceptions of what this whole project has been about, they are going to say this has been a big brother project. It's been a way to keep a track on us, so if I'm not performing they can sack me.

IS: No! What I get from time based [costing], the impression I got, costing is a report so we can get extra funding from the government.

User 1: I know what you are telling me P. What I am saying is, I brought this up the first time you mentioned it, that I thought it would not be a good idea, to be in this project, because people are going to see this whole project as being based around that particular item.

User 3: What we want is it to be taken on, and feel good about it, without feeling paranoid about it.

User 1: That's right.

User 3: Because they are already paranoid about it. . .

User 1: They are going to sabotage it. 
U3: Yes, sabotage it or something.

(Transcript of user group meeting).

In the transcript from this meeting, we can see that the IS project leader tried to play down the significance of the time-based costing module (e.g., "it is very small, it's just a print-out that's all"), while at the same time acknowledging the business imperative for its use (e.g., "the impression I got, costing is a report so we can get extra funding from the Government"). The project leader also made it sound as if the introduction of the time-based costing module was inevitable ("Yes, that will be included"). The members of the user group, on the other hand, were surprised and annoyed that they had not been consulted earlier. As clinicians, they had ostensibly participated in the development of the system as user representatives, and until now the time-based costing module had not been mentioned. They were concerned that their fellow clinicians might perceive their participation in development as complicity in the introduction of time-based costing. Consequently, it was agreed at this same user group meeting (a little later on) that time-based costing should be kept as a separate module or introduced later when users had become accustomed to the system. The clinicians argued that the success of the mental health project could be jeopardized if time-based costing were introduced too early and users were not clearly aware of its purpose.

In a subsequent interview one user group member discussed the time-based costing module as follows:

If time-based costing is put in, then it's going to be a problem with [the marketing of this system], because people are going to have a perception of what this computer system is all about....The perception has been, as an auditing service, as an accounting service, as a way of tracking people I mean, that is the general sort of feeling about computers in organisations. In this system it [was not intended to be] that at all, but it could easily be perceived as such...I don't think it will be a problem, it will be brought up in the next meeting - we'll get it sidelined!

This clinician expresses the view that if the time-based costing module is included in the project, it will lead to significant problems in users' acceptance of it. The "general sort of feeling" among the clinical staff would be that computers are being used yet again to further control professional people. However, this clinician expressed confidence in his ability (and that of the other clinicians) to get the time-based costing module sidelined at the next meeting. This tactic was successful to a certain extent: the time-based costing module was still to be included, but at least it was agreed not to include it during the initial roll-out of the mental health information system.

Although a significant number of clinical staff opposed the government's reforms in the health sector, and by implication the information systems that were to be developed to put these reforms into practice, this was not true of everyone. Almost all the doctors and nurses chosen to be on the user group and project team were 
generally enthusiastic about the potential for information systems to improve clinical practice. These clinicians also tended to be sympathetic to the goals of both information services and mental health management. Also, while the project team members were drawn from various stakeholder groups (managers, IS, clinical and clerical users, etc.), the team members developed more of a loyalty to each other and to the project as time went on. The same process occurred within the user group. Despite the fact that the user group was theoretically supposed to represent users, the user group members started to identify more with each other and with the system as the project progressed. In other words, as members of the project team and user group continued to invest their time and effort in the development of the system, they developed more of a vested interest in it.

Seen in this light, the clinicians involved with the project were not opposed to the introduction of new information systems or time-based costing per se; rather, they were more concerned about how the project (and their involvement with it) would be perceived by their clinical colleagues. By being involved with the project as user representatives, they had given a certain amount of legitimacy to the development of the mental health information system. If time-based costing were to be included in the current project, not only would their peers question the legitimacy of the project, they would question their own credibility as well.

That there were developing coalitions of stakeholders (top management, information services, clinical and clerical users) as the system progressed throws into question one of the traditional assumptions of most critical management theorists: that organizational participants can be categorized into distinct groups and that these groups are opposed (often necessarily so) because of the underlying economic and power relations (e.g., Alvesson and Willmott 1992). An example of the latter is the (otherwise excellent) analysis by Broadbent, Laughlin and Read of the financial and administrative changes in the National Health Service in the United Kingdom. The authors assume that "performance-pay related managers" have interests which are distinct and opposed to those of doctors. They suggest that, whereas the former are interested in controlling expenditure and ultimately doctors' clinical practice, the latter are most of all concerned with clinical freedom.

As we have seen, the critical ethnographic research conducted by Young showed that not all doctors were opposed to the goals of management or to the mental health information system. The mental health information system was successfully implemented with the input and support of doctors and nurses on the project team and user group. This is not to say that all doctors and nurses supported the new information system, but the development of the system was legitimized by the support and participation of those who did. Even though those clinicians who participated in the project were unhappy with the attempt by management and IS to have the time-based costing module included in the initial roll-out of the mental health information system, they were not opposed to the system per se.

The previous discussion draws attention to the inherently political nature of information systems development and how terms such as user involvement and 
participation can mask the deeper political and cultural processes within which IS development is embedded. After the user group had succeeded in sidelining the timebased costing module to a later implementation date, the champion (a senior manager) commented:

The usergroup felt that it was too much to ask the staff to get used to both the implementation of the information system and recording of their statistics in a new way.

Political opposition to time-based costing was thus reinterpreted by management as staff difficulty in adjusting to new information systems. The key problem was thus cleverly shifted from being one of system goals to the more politically neutral one of user acceptance.

\section{DISCUSSION}

In commenting on the critical ethnographic study reviewed above, a number of important points can be made.

First, the ethnographer was expressly situated in history. The system studied was intimately tied up with a wider set of social, economic and political relationships involving the New Zealand government's reforms of the health sector. The use of the ethnographic present to describe what the ethnographer saw and heard would have been nonsensical, given that the object of study was a moving target (an IS project). The ethnography was therefore written in the past tense (e.g., as soon as a meeting had finished, it was already history).

Second, the ethnography was critical in a number of ways. The ethnographer exposed the hidden agenda of senior management to introduce time-based costing despite not including this module in the initial user requirements document. Some commonsense assumptions about information systems development were also questioned, e.g., user involvement in this organization was as much about legitimizing the system as it was about obtaining user input. Further, the idea common in critical management studies that organizational stakeholder groups (such as management and doctors) are often necessarily opposed because of the underlying economic and power relations was shown to be somewhat simplistic. While this is true to a certain extent, it does not explain the support of those clinicians on the project team and usergroup for the mental health information system as a whole.

\section{CONCLUSION}

This paper has discussed the nature and applicability of a relatively new qualitative approach to information systems research called critical ethnography. Ethnographic research is a useful method for analyzing the institutional contexts of information 
systems practices, with the notion of context being the social construction of meaningful frameworks. When the form of ethnographic research known as critical ethnography is used (although this is not the only one), the findings can be scrutinized for otherwise hidden agendas, power centers and other taken for granted aspects of social reality.

This paper looked at one critical ethnographic study of the development of an information system in mental health. The new system was shown to contain within itself the hidden agendas of management, and more broadly of the New Zealand government. This study raises broader questions about the social and political nature of information systems development, such as the extent to which hidden agendas, power centers and managerial assumptions inhibit, repress and constrain user involvement and user participation. In the example of the specific IS discussed in this paper, the system penetrated most deeply into the social processes of cultural control (cf. Thomas 1993, p. 60; Orlikowski 1991).

\section{REFERENCES}

Alavi, M., and Carlson, P. (1992), "A Review of MIS Research and Disciplinary Development." Journal of Management Information Systems, Volume 8, Number 4, pp. 45-62.

Alvesson, M., and Willmott, H. (Editors) (1992). Critical Management Studies. London: Sage Publications.

Avison, D. E., and Myers, M. D. (1995). "Information Systems and Anthropology: An Anthropological Perspective on IT and Organizational Culture." Information Technology and People, Volume 8, Number 3, pp. 43-56.

Banville, C., and Landry, M. (1989). "Can the Field of MIS be Disciplined?" Communications of the ACM, Volume 32, Number 1, pp. 48-60.

Barley, S. R. (1986). "Technology as an Occasion for Structuring: Evidence from Observations of CT Scanners and the Social Order of Radiology Departments." Administrative Science Quarterly, Volume 31, Number 1, pp. 78-108.

Benbasat, I.; Goldstein, D. K.; and Mead, M. (1987). "The Case Research Strategy in Studies of Information Systems." MIS Quarterly, Volume 11, Number 3, pp. 369-386.

Bentley, R.; Rodden, T.; Sawyer, P.; Sommerville, I.; Hughes, J.; Randall, R.; and Shapiro, D. (1992). "Ethnographically-Informed Systems Design for Air Traffic Control." In CSCW '92. ACM 1992 Conference on Computer-Supported Cooperative Work: Sharing Perspectives. New York: ACM Press, 123-129.

Bernstein, R. J. (1983). Beyond Objectivism and Relativism. Philadelphia: University of Pennsylvania Press. 
Boland, R. (1985). "Phenomenology: A Preferred Approach to Research in Information Systems." In E. Mumford, R. A. Hirschheim, G. Fitzgerald, and T. WoodHarper (Editors), Research Methods in Information Systems. Amsterdam: NorthHolland.

Boland, R. (1987). “The In-formation of Information Systems." In R. J. Boland and R. A. Hirschheim (Editors), Critical Issues in Information Systems Research. New York: John Wiley and Sons.

Boland, R. (1991). "Information System Use as a Hermeneutic Process." In H-E. Nissen, H. K. Klein, and R. A. Hirschheim (Editors), Information Systems Research: Contemporary Approaches and Emergent Traditions. Amsterdam: NorthHolland.

Boland, R. J., and Day, W. F. (1989). "The Experience of System Design: A Hermeneutic of Organizational Action." Scandinavian Journal of Management, Volume 5, Number 2, pp. 87-104.

Broadbent, J.; Laughlin, R.; and Read, S. (1991). "Recent Financial and Administrative Changes in the NHS: A Critical Theory Analysis." Critical Perspectives on Accounting, Volume 2, pp. 1-29.

Bryman, A. (1989). Research Methods and Organization Studies. London: Unwin Hyman

Clifford, J. (1988). The Predicament of Culture: Twentieth-Century Ethnography, Literature and Art. Cambridge, Massachusetts: Harvard University Press.

Clifford, J. and Marcus, G. E. (1986). Writing Culture: The Poetics and Politics of Ethnography. Berkeley: University of California Press.

Clausen, J.; Domney, M.; and Pederson, M. (1992). "Auckland Area Health Board: The Enterprise Network." Unpublished MBA Working Paper, University of Auckland.

Cohen, A. P. (1985). The Symbolic Construction of Community. London: Ellis Horwood.

Danzon, P., and Begg, S. (1991). "Options for Health Care in New Zealand.” Report for the Business Roundtable, Wellington, April.

Davies, L. J. (1991). "Researching the Organizational Culture Contexts of Information Systems Strategy." In H-E. Nissen, H. K. Klein, and R. A. Hirschheim (Editors), Information Systems Research: Contemporary Approaches and Emergent Traditions. Amsterdam: North-Holland.

Davies, L. J., and Nielsen, S. (1992). "An Ethnographic Study of Configuration Management and Documentation Practices in an Information Technology Center." In K. E. Kendall, K. Lyytinen, and J. I. DeGross (Editors), The Impact of Computer Supported Technology on Information Systems Development. Amsterdam: North-Holland.

Evans-Pritchard, E. E. (1950). Witchcraft, Oracles and Magic among the Azande. Oxford: The Clarendon Press. 
Forester, J. (1992). "Critical Ethnography: On Field Work in an Habermasian Way." In M. Alvesson and H. Willmott (Editors), Critical Management Studies. London: Sage Publications.

Frost, P. J.; Moore, L. F.; Louis, M. R.; Lundberg, C. C.; and Martin, J. (Editors) (1985). Organizational Culture. Beverly Hills: Sage Publications.

Gadamer, H-G. (1976a). Philosophical Hermeneutics. Berkeley: University of California Press.

Gadamer, H-G. (1976b). "The Historicity of Understanding." In P. Connerton (Editor), Critical Sociology: Selected Readings. Harmondsworth, England: Penguin Books Ltd.

Galliers, R. D. (1991). "Choosing Appropriate Information Systems Research Methods." In H-E. Nissen, H. K. Klein, and R. A. Hirschheim (Editors), Information Systems Research: Contemporary Approaches and Emergent Traditions. Amsterdam: North-Holland.

Galliers, R. D., and Land, F. F. (1987). "Choosing Appropriate Information Systems Research Methodologies." Communications of the ACM, Volume 30, Number 11, pp. 900-902.

Geertz, C. (1973). The Interpretation of Cultures. New York: Basic Books.

Geertz, C. (1983). Local Knowledge: Further Essays in Interpretive Anthropology. New York: Basic Books.

Geertz, C. (1988). Works and Lives: The Anthropologist as Author. Cambridge, England: Polity Press.

Harvey, L., and Myers, M. D. (1995). "Scholarship and Practice: The Contribution of Ethnographic Research Methods to Bridging the Gap." Information Technology and People, Volume 8, Number 3, pp. 13-27.

Hirschheim, R., and Klein, H. K. (1989). "Four Paradigms of Information Systems Development." Communications of the ACM, Volume 32, Number 10, pp. 11991216.

Hirschheim, R., and Newman, M. (1991). "Symbolism and Information Systems Development: Myth, Metaphor and Magic." Information Systems Research, Volume 2, Number 1, pp. 29-62.

Holzblatt, K., and Beyer, H. (1993). "Making Customer-Centered Design Work for Teams." Communications of the ACM, Volume 36, Number 10, pp. 93-103.

Hoy, T. (1988). Praxis, Truth, and Liberation. Lanham: University Press of America.

Hughes, J. A.; Randall, D.; and Shapiro, D. (1992). "Faltering from Ethnography to Design." CSCW'92 ACM : 1992 Conference on Computer-Supported Cooperative Work: Sharing Perspectives. New York: ACM Press, pp. 115-123.

Hutchins, E. (1995). Cognition in the Wild. Cambridge, Massachusetts: MIT Press.

Kahn, J. S. (1989). "Culture: Demise or Resurrection?" Critique of Anthropology, Volume 9, Number 2, pp. 5-25. 
Landry, M., and Banville, C. (1992). "A Disciplined Methodological Pluralism for MIS Research." Accounting, Management and Information Technologies, Volume 2, Number 2, pp. 77-97.

Lee, A. S. (1991). "Integrating Positivist and Interpretive Approaches to Organizational Research." Organization Science, Volume 2, pp. 342-365.

Lee, A. S. (1994). "Electronic Mail as a Medium for Rich Communication: An Empirical Investigation Using Hermeneutic Interpretation." MIS Quarterly, Volume 18, Number 2, pp. 143-157.

Lee, A. S.; Baskerville, R. L.; and Davies, L. (1992). "A Workshop on Two Techniques for Qualitative Data Analysis: Action Research and Ethnography." In J. I. DeGross, J. D. Becker, and J. J. Elam (Editors), Proceedings of the Thirteenth International Conference on Information Systems, December 13-16, Dallas, Texas, pp. 305-306.

Lewis, I. M. (1985). Social Anthropology in Perspective. Cambridge, England: Cambridge University Press.

Marcus, G. E. (1992). Rereading Cultural Anthropology. Durham, North Carolina: Duke University Press.

Marcus, G. E., and Fischer, M. M. (1986). Anthropology as Cultural Critique. Chicago: Chicago University Press.

Myers, M. D. (1987,). Independens Long Vanuatu: The Churches and Politics in a Melanesian Nation. Unpublished Ph.D. Thesis, University of Auckland.

Myers, M. D. (1994). “A Disaster for Everyone to See: An Interpretive Analysis of a Failed IS Project." Accounting, Management and Information Technologies, Volume 4, Number 4, pp. 185-201.

Myers, M. D. (1995). "Dialectical Hermeneutics: A Theoretical Framework for the Implementation of Information Systems." Information Systems Journal, Volume 5, Number 1, pp. 51-70.

Myers, M. D., and Young, L. W. (1995). "The Implementation of an Information System in Mental Health: An Ethnographic Study." Proceedings of the Australasian Conference on Information Systems, September 27-29, Perth, pp. 779-792.

Newman, M., and Robey, D. (1992). "A Social Process Model of User-Analyst Relationships." MIS Quarterly, Volume 16, pp. 249-266.

Orlikowski, W. J. (1991). "Integrated Information Environment or Matrix of Control? The Contradictory Implications of Information Technology." Accounting, Management and Information Technologies, Volume 1, Number 1, pp. 9-42.

Orlikowski, W. J., and Baroudi, J. (1991). "Studying Information Technology in Organizations: Research Approaches and Assumptions." Information Systems Research, Volume 2, Number 1, pp. 1-28.

Pettigrew, A. M. (1985). "Contextualist Research and the Study of Organizational Change Processes." In E. Mumford, R. Hirschheim, G. Fitzgerald, and A. T. Wood-Harper (Editors), Research Methods in Information Systems. Amsterdam: North-Holland. 
Power, M. K. (1991). "Educating Accountants: Towards a Critical Ethnography." Accounting, Organizations and Society, Volume 16, Number 4, pp. 333-353.

Preston, A.M. (1991). "The 'Problem' in and of Management Information Systems." Accounting, Management and Information Technologies, Volume 1, Number 1, pp. 43-69.

Radnitzky, G. (1970). Contemporary Schools of Metascience. Goteborg: Scandinavian University Books.

Ricoeur, P. (1974). The Conflict of Interpretations: Essays in Hermeneutics. Evanston, Illinois: Northwestern University Press.

Sanday, P. R. (1979). "The Ethnographic Paradigm(s)." Administrative Science Quarterly, Volume 24, Number 4, pp. 527-538.

Scholte, B. (1972). "Toward a Reflexive and Critical Anthropology." In D. Hymes (Editor), Reinventing Anthropology. New York: Random House Inc.

Star, S. L. (1995). Cultures of Computing. Oxford: Blackwell.

Suchman, L. (1987). Plans and Situated Actions: The Problem of Human-Machine Communication. Cambridge, England: Cambridge University Press.

Suchman, L. (1995). "Making Work Visible." Communications of the ACM, Volume 38 , Number 9, pp. 56-64.

Taylor, C. (1976). "Hermeneutics and Politics." In P. Connerton (Editor), Critical Sociology: Selected Readings. Harmondsworth, England: Penguin Books Ltd.

Thomas, J. (1983). "Toward a Critical Ethnography." Urban Life, Volume 11, Number 4, pp. 477-490.

Thomas, J. (1993). Doing Critical Ethnography. Newbury Park, California: Sage Publications.

Thompson, J. B. (1981). Critical Hermeneutics: A Study in the Thought of Paul Ricoeur and Jurgen Habermas. Cambridge, England: Cambridge University Press.

Van Maanen, J. (1988). Tales of the Field: On Writing Ethnography. Chicago: University of Chicago Press.

Upton, S. (1991). Your Health and the Public Health: A Statement of Government Health Policy. Wellington, New Zealand: Minister of Health.

Walsham, G. (1993). Interpreting Information Systems in Organizations. Chichester, England: Wiley.

Walsham, G. (1995a). "Interpretive Case Studies in IS Research: Nature and Method." European Journal of Information Systems, Volume 4, pp. 74-81.

Walsham, G. (1995b). "The Emergence of Interpretivism in IS Research." Information Systems Research, Volume 6, Number 4, pp. 376-394.

Walsham, G., and Waema, T. (1994). "Information Systems Strategy and Implementation: A Case Study of a Building Society." ACM Transactions on Information Systems, Volume 12, Number 2, pp. 150-173.

Winograd, T., and Flores, F. (1987). Understanding Computers and Cognition: A New Foundation for Design. Reading, Massachusetts: Addison-Wesley Publishing Co. Inc. 
Wynn, E. (1979). Office Conversation as an Information Medium. Unpublished Ph.D. Dissertation, University of California, Berkeley.

Wynn, E. (1991). “Taking Practice Seriously.” In J. Greenbaum and M. Kyng (Editors), Design at Work. Hillsdale, New Jersey: Lawrence Erlbaum.

Yin, R. K. (1989). Case Study Research: Design and Methods. Newbury Park, California: Sage Publications.

Young, L. W. (1995). The Implementation of an Information System in Mental Health: A Critical Hermeneutic Interpretation. Unpublished Masters Thesis, University of Auckland, Auckland.

Zuboff, S. (1988). In the Age of the Smart Machine. New York: Basic Books.

\section{BIOGRAPHY}

Michael D. Myers is senior lecturer in the Department of Management Science and Information Systems at the University of Auckland. He has an M.A. and Ph.D. in Social Anthropology from the University of Auckland. Before joining the university in 1989, he worked for IBM New Zealand Ltd. Dr. Myers is editor of the ISWorld Section on Qualitative Research. 